\title{
Measurement Method of the Width of the Strands of Cut Tobacco Based on Digital Image Processing *
}

\author{
by \\ Jun Liu ${ }^{1}$, Zhihao Chen ${ }^{2}$, Jijun Zhao ${ }^{2}$, Shu Wang ${ }^{3}$, Li Ding $^{2}$, Xiaosong Wu ${ }^{3}$, Long Zhang ${ }^{3}$, and Qian Feng ${ }^{2}$ \\ ${ }^{1}$ Tobacco Quality Supervision and Test Station, Guangdong Tobacco Monopoly Bureau, Guanzhou 510610, China \\ ${ }^{2}$ Zhengzhou Tobacco Research Institute of CNTC, Zhengzhou 450001, Henan, China \\ ${ }^{3}$ HeFei Institute of Physical Science, CAS, HeFei 230031, China
}

\section{SUMMARY}

The width of cut tobacco strands is an important indicator for physical parameters as well as for the smoking quality. In some countries, cut width helps to distinguish fine-cut tobacco and pipe tobacco and thus differentiates taxation rate. A new method for rapid measurement of the width of cut tobacco strands was developed based on digital image processing, because the method described in ISO 20193, though easy to implement in factories, proved time consuming and generated high testing costs. The essence of this method is to determine the statistic width of incisions. The straight-line segments represent the width of strands of cut tobacco, from which the determination of the width for randomly placed tobacco strands could be achieved. Five kinds of samples ('ISO collaborative study samples $0.4 \mathrm{~mm}, 1.0 \mathrm{~mm}, 1.6 \mathrm{~mm}$ and $3.0 \mathrm{~mm}$ ' and 'Guangdong baked $0.9 \mathrm{~mm}$ ') were used to study the comparability of the measurement results between the method presented in this work and the current ISO method. Results show that accuracy and repeatability are comparable. In addition, the testing efficiency of the method presented in this work appears to be higher than the current ISO method, and it is thus a promising alternative method for measuring the width of strands of cut tobacco. [Beitr. Tabakforsch. Int. 28 (2019) 278-285]

\section{ZUSAMMENFASSUNG}

Die Fadenbreite von Schnitttabak ist ein wichtiger Indikator für die physikalischen Parameter sowie die Rauchqualität. In einigen Ländern ermöglicht die Schnittbreite die Unterscheidung von Feinschnitttabak und Pfeifentabak und damit die Anwendung unterschiedlicher Steuersätze. Auf der Grundlage der digitalen Bildverarbeitung wurde eine Methode zur schnellen Messung der Fadenbreite von Schnitttabak entwickelt, da die in ISO 20193 beschriebene Methode zwar einfach in der Fabrik umzusetzen ist, jedoch einen hohen Zeit- und Prüfaufwand erfordert. Das Hauptmerkmal dieser Methode ist die Bestimmung der statistischen Breite der Schnitte, die geradlinigen Segmente würden hierbei die Breite der Schnitttabakfäden repräsentieren. Auf dieser Grundlage könnte die Breite von zufällig ausgewählten und platzierten Tabakfäden ermittelt werden. Es wurden fünf Arten von Stichproben ('ISO Ringversuch Stichproben mit 0,4 mm, 1,0 mm, 1,6 mm und 3,0 mm' und 'Guangdong ofengetrocknet $0,9 \mathrm{~mm}$ ') verwendet, um die Vergleichbarkeit der Messergebnisse der in dieser Arbeit 
vorgestellten Methode und der aktuellen ISO-Methode zu untersuchen. Die Ergebnisse zeigen, dass die Genauigkeit und Wiederholbarkeit vergleichbar sind. Zusätzlich scheint die Prüfeffizienz der hier vorgestellten Methode höher zu sein als bei der aktuellen ISO-Methode. Sie ist daher eine vielversprechende alternative Methode zur Bestimmung der Fadenbreite von Schnitttabak. [Beitr. Tabakforsch. Int. 28 (2019) 278-285]

\section{RESUME}

La largeur des brins de tabac haché constitue un indicateur essentiel de leurs paramètres physiques et de la qualité du fumage. Dans certains pays, la largeur de coupe contribue à distinguer le tabac à coupe fine du tabac à pipe ainsi que les taux d'imposition différenciés. Une méthode de mesure rapide de la largeur des brins de tabac haché a été développée prenant appui sur le traitement numérique des images; sachant que la méthode exposée dans la norme ISO 20193 se prête, certes, facilement à une application en usine mais s'avère chronophage et associée à des coûts d'essais élevés. En substance, cette méthode détermine la largeur statistique des incisions, les segments rectilignes pourraient représenter la largeur des brins de tabac haché à partir de laquelle la largeur des brins de tabac disposés de façon aléatoire pourrait être déterminée. Cinq types d'échantillons (échantillons d'étude collective de l'ISO 0,4 mm, 1,0 mm, $1,6 \mathrm{~mm}$ et 3,0 mm et 'Guangdong séché au four $0,9 \mathrm{~mm}$ ') furent utilisés lors de l'analyse de la comparabilité des résultats de mesure mettant en regard le procédé exposé dans le présent article et la méthode ISO actuelle. Les résultats démontrent que la précision et la répétabilité sont comparables. En outre, l'efficacité des essais dans le cas du procédé exposé dans le présent article semble être supérieure à celle de la méthode ISO actuelle. Ce procédé constitue, dès lors, une méthode alternative prometteuse pour la mesure de la largeur des brins de tabac haché. [Beitr. Tabakforsch. Int. 28 (2019) 278-285]

\section{INTRODUCTION}

The width of cut tobacco strands is an important indicator for filling value, 'tar' and dust content of cigarettes $(1,2)$. In some countries, cut width helps to distinguish fine-cut tobacco and pipe tobacco and thus differentiates taxation rates. The determination of the width of cut tobacco strands plays a significant role in quality control of tobacco cutting and physical parameters of tobacco strands. It is also of great importance for saving raw tobacco (3). In this regard, a method for determination of the width of the strands of cut tobacco is described in ISO 20193 (4). This standard specifies the procedures of sampling, accuracy of tools and an example of a sample holder. Currently, a microscope with an internal fitted ruler is commonly used in factories and laboratories. This device, though easy to implement in the production, is rather time consuming and generates high testing cost. On the other hand, a method for the determination of the width of the strands of cut tobacco based on digital image processing (DIP) could result in higher efficiency $(5,6)$. Thus, it is of potential value to develop and assess a new method to determine the width of the strands of cut tobacco based on the digital image processing.

In order to conduct an efficient measuring process, a method based on DIP was developed, and its principles are described in detail in this paper. Firstly, the distortion image was recovered via Zhang's calibration method $(7,8)$. Then the Mean-shift algorithm was used to enhance the quality of images and to segment the strands of cut tobacco from the background accurately (9). Subsequently, the Hough transform-based algorithm for recognition of the cut position on cut tobacco was proposed and the measurement-points of width were screened out automatically (10). Then the final measuring was realized by detecting the matching pair of lines (11).

\section{MATERIALS AND PROCEDURES}

\subsection{Apparatus}

The DIP setup used in this work is shown in Figure 1. A 2D-array CCD camera (ImagingSource, Bremen, Germany) with a resolution of 111,000 pixels $\mathrm{cm}^{-2}$, a standard lens (Fujifilm HF12.5SA-1, Tokyo, Japan), a CPU, LED light and a sample holder were installed in the setup in order to meet all requirements for measuring. In detail, high lumen intensity was achieved by using white ( $5500 \mathrm{~K})$ LED light, and a black board was used as support table and imaging background. The sample holder was fixed on the slide rail which could be pulled out. Tobacco strands were randomly placed in a specified area, carefully avoiding any overlapping, and covered by a glass board in order to have the strands laid down flat. A ruler with a resolution of $0.01 \mathrm{~mm}$ and an accuracy of $0.05 \mathrm{~mm}$ was used as a standard to calibrate the scale of the field.

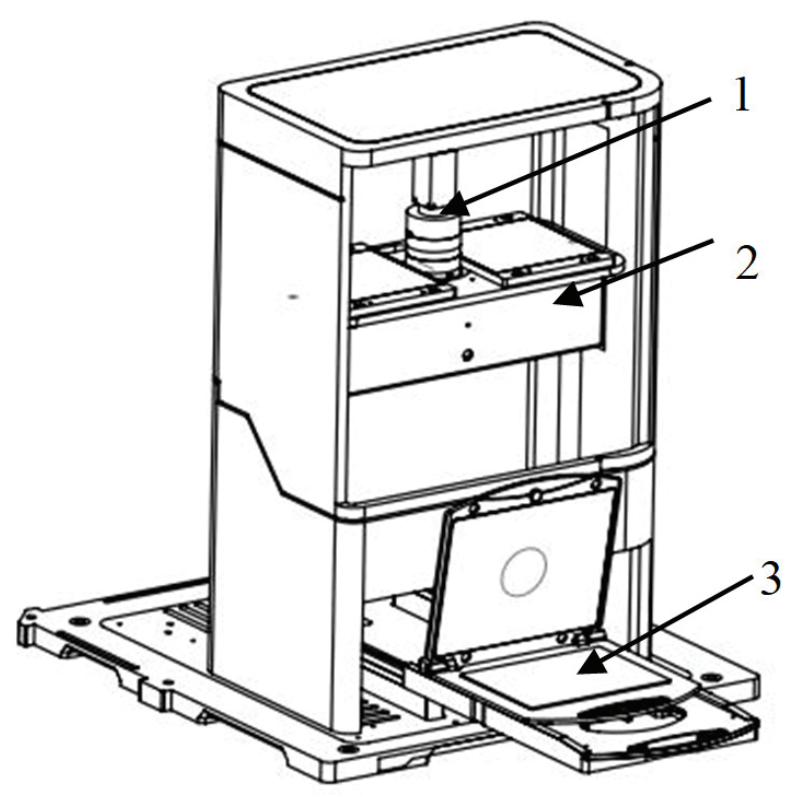

Figure 1. Structure of a digital image processing system. 1. Camera lens; 2. LED light; 3 . Sample holder (including a background board and a glass cover). 


\subsection{Strands of cut tobacco}

The strands of cut tobacco used in this work were 'ISO collaborative study samples' and 'Guangdong baked $0.9 \mathrm{~mm}$ ' (a sample with cut width of $0.9 \mathrm{~mm}$ from Guangdong Province, China), as listed in Table 1.

Table 1. Strands of cut tobacco used in this work.

\begin{tabular}{lc}
\hline Samples & Width / (mm) \\
\hline ISO 1 & 0.4 \\
ISO 2 & 1.0 \\
ISO 3 & 1.6 \\
ISO 4 & 3.0 \\
'Guandong baked' & 0.9 \\
\hline
\end{tabular}

\subsection{Procedures for the determination of the width of strands of cut tobacco}

Sampling procedure was first applied according to ISO 20193 (4). Subsequently, samples (usually 30 strands) were randomly selected and placed on the sample holder without any overlapping, and a pure quartz glass board with a thickness of $1 \mathrm{~mm}$ was lightly placed on the samples. The glass board could be adjusted to lay the strands down flat. Noteworthy: This is much simpler in comparison to the sample preparation procedure described in ISO 20193, since the process of straightening and pasting the tobacco strands is not necessary. After placing the samples, the following steps were run automatically by the computer. Firstly, the images of strands of cut tobacco were segmented and highlighted based on the Mean-shift algorithm. Then the contours of segmented images were labeled and extracted using a region-growing algorithm based on eight-neighbors. After that, the line pairs of the edges of cut tobacco strands were identified via the Hough transform algorithm, from which the width of the strands of cut tobacco could be calculated.

\section{PRINCIPLES}

\subsection{Recovering the distorted images}

The imaging background used in this work consisted of a square of $155 \mathrm{~mm} \times 155 \mathrm{~mm}$. In order to carry out precise measurements, uniform imaging of different areas on the sample plate had to be achieved. Therefore, the image processing system was calibrated to eliminate the distortion effect. Under current practice, the calibration could be accomplished by either a standard template method (12) or a nonstandard template method (13). The distortion parameters set by the first type of method were based on the transformation of a standardized template. And the distortion parameters set by the nonstandard method were based on the process of recovering a distorted curve to a straight line. The Zhang's calibration method used in this work belongs to the standard template method, and the principle could be explained as equation [1]:

$$
s\left[\begin{array}{l}
u \\
v \\
1
\end{array}\right]=K\left[\begin{array}{lll}
r_{1} & r_{2} & r_{3} t
\end{array}\right]\left[\begin{array}{l}
X \\
Y \\
0 \\
1
\end{array}\right]=K\left[\begin{array}{lll}
r_{1} & r_{2} & t
\end{array}\right]\left[\begin{array}{c}
X \\
Y \\
1
\end{array}\right]
$$

where $[u, v]$ is a point on the calibration board; $[X, Y, 1]^{T}$ are its homogeneous coordinates; $[u, v, 1]^{T}$ are the homogeneous coordinates of the projection point on the imaging plane of $[u, v] ; s$ means the ratio from calibration board to imaging plane; $\left[r_{1}, r_{2}, r_{3}\right]$ and $t$ are the rotation matrix and translation matrix, respectively, and $K$ is the intrinsic parameter matrix of the camera. Equation [1] is valid assuming that the standard template plane is the same as the plane of $Z=0$ in the world coordinate system. This method is applied via the following principles (14):

1) A square plate with a checkerboard pattern was prepared, its size was $110 \times 110 \mathrm{~mm}$ and the side lenght of the black and white squares was $10 \mathrm{~mm}$, respectively;

2) The checkerboard plate was placed in different positions of the imaging background, and images were individually collected;

3) Intrinsic parameters and extrinsic parameters were calculated based on the feature points (vertexes of black/white squares) of all the images in the checkerboard plate;

4) The recovery correction factor was calculated.

Based on the aforementioned principles, the recovering effect was examined and the images before and after recovery are shown in Figure 2.
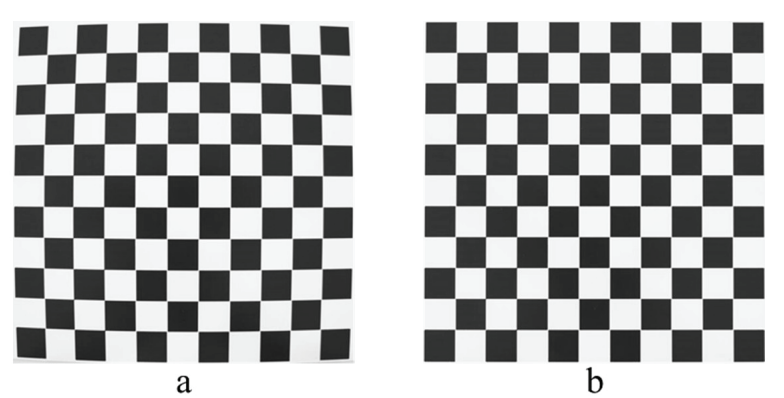

Figure 2. Recovering the distorted checkerboard image. (a) before recovery; (b) after recovery

As can be seen in Figure 2 (a), a typical barrel distortion was observed. However, from Figure 2 (b), the curved edges were recovered into flat edges, proving a valid recovering effect of this method.

\subsection{Segmenting the images of strands of cut tobacco}

With the DIP method, segmentation is necessary to select the chosen area, which is prepared for the subsequent labeling and extraction processes. Tobacco strands tested in this work were mainly yellow or brown, the background board was black. The originally collected and rectified image of the cut tobacco strands is shown in Figure 3 (a). Typically, when the strands' images needed to be segmented, the colored images were first converted into grayscale images. Afterwards they could be segmented using 
either the adaptive thresholding method or a screening method based on color feature difference $(15,16)$. However, there are several similar colors between the strands and the background due to pigmentation of the strands and imaging angles. These lead to relatively poor results of segmentation with noise and breakages as shown in Figure 3 (b).
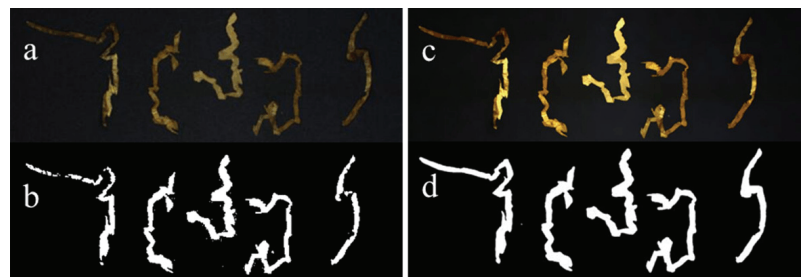

Figure 3. Segmentation of the cut tobacco strands as an example for the extraction of the whole sample holder field. (a) and (b): the original images of cut tobacco strands and their segmentation results, respectively; (c) and (d): the images of cut tobacco strands and their segmentation results after having been processed with Mean-shift algorithm, respectively.

After analyzing the image features of the tobacco strands, a method based on the Mean-shift algorithm was used in this work $(17,18)$. It transformed the RGB image into gray scale, thus avoiding sensitivity issues and errors due to the different colors of the samples. The principle of this method is to highlight the region of interest (ROI) and to inhibit the noise in the background. The targeted areas were then extracted through the threshold segmentation method. The Mean-shift algorithm can be illustrated with equation [2]:

$$
f_{h}(x)=\frac{\sum_{i=1}^{n} K_{1}\left(\frac{x_{i}^{c}-x^{c}}{h}\right) K_{2}\left(x_{i}^{p}\right) x_{i}^{c}}{\sum_{i=1}^{n} K_{1}\left(\frac{x_{i}^{c}-x}{h}\right) K_{2}\left(x_{i}^{p}\right)}
$$

where $x^{c}$ stands for the parameters of pixel points to be analyzed; $x_{i}^{c}$ and $x_{i}^{p}$ are the color and distance parameters of pixel points to be analyzed, respectively; $K_{1}(x)$ is the diversity towards the color of point $x$, which would be increased when the color was close to point $x ; K_{2}(x) \geq 0$ is the diversity towards the position of point $x$, which would be increased when it was near point $x ; h$ is the surface of the processed area. For clarification: the function $f_{h}(x)$ is a basic principle of the Mean-shift algorithm. When this algorithm is applied, a minimum threshold value of pixels merged needs to be set, which depends on the contrast between targeted area and background area within the image. The processed images after applying the Mean-shift algorithm are shown in Figure 3 (c) and (d). It is clear that the Mean-shift algorithm exhibited better segmentation results and fitted well with the original shape of the tested tobacco strands.

\subsection{Labeling and contour extraction}

There are several strands of cut tobacco for measurement from one image per measuring procedure whereas the algorithm is only applicable to single strands of cut tobacco. Therefore, it is necessary to label and extract the contours to distinguish the strands. In order to label the different tobacco strands in the image, a connected-component labeling method was applied for the segmented images (19). In particular, a region growing algorithm based on eight-neighbor pixels was used in this work $(20,21)$. First, all sub-pathways for the initial node were located. While looking for new nodes, the one on the same level with the initial node was set as the first target. After that, the node on the next level was sought. The detailed process is detailed here after:

1) Raster scanning was applied on the image of tobacco strands. The first scanned pixel point was considered the initial connected-component point, from which coordinates as well as direction information were labeled. Then this specific strand was tracked, and a relevant Chain Code was calculated. For clarification: Chain Code (also known as Freeman Chain Code) is a method to describe curves or boundaries by using the coordinates of the starting points of curves and the direction codes of boundary points. It is commonly used to express curves and regional boundaries in the fields of image processing, computer graphics and pattern recognition;

2) According to the priority of nodes as mentioned above, all sub-pathways for the initial node were tracked and accessed. During this procedure, all nodes with the same level from other directions were saved and labeled. On the other hand, other points with higher priority were continuously tracked and all visited points were labeled;

3) Step 2 was repeated until all the points in this connectedcomponent were labeled. Then the tracking was considered complete and the process returned to step 1;

4) Labeling of all the tracked and calculated connectedcomponents was started. Identical connected-components were labeled with gray-scale.

Based on the aforementioned principles, images of strands of cut tobacco which have been labeled with connectedcomponents are shown in Figure 4. It shows that images of strands of cut tobacco were successfully labeled and could therefore be differentiated from the background.

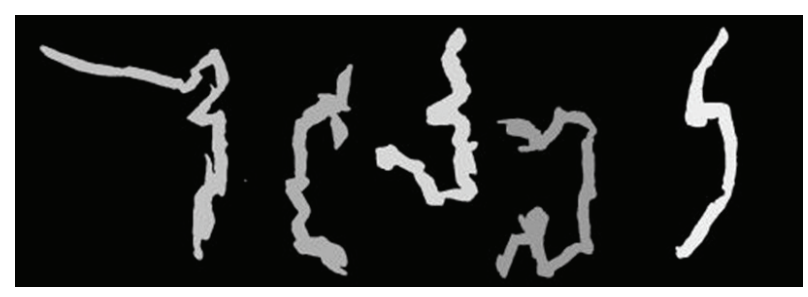

Figure 4. Image of strands of cut tobacco labeled with connected-component.

Furthermore, a morphological gradient-based method was applied to achieve the accurate extraction of the contours of tobacco strands $(22,23)$. Aiming at binary images, an edge detection algorithm was proposed based on the morphological open-closed operation. Struct $E$ is a group of $3 \times 3$ matrices. Through the combination of 9 values in the matrix, different convolution matrices are formed and convoluted with the original image, which is used to erode the binary image (24). On this basis, the eroded images were subtracted by the original images to obtain the contour 
of strands of cut tobacco. The mathematical model is listed in equation [3]:

$$
\text { Edge }(f(x, y))=f(x, y)-f(x, y) \theta \text { Struct_E }
$$

where $E d g e(f(x, y))$ is the pixel point of the contour; $\theta$ is the operative symbol of eroding. By applying this algorithm, the contour of tobacco strands was extracted as shown in Figure 5.

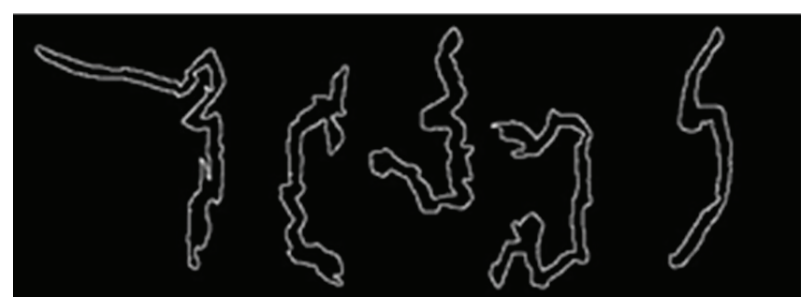

Figure 5. Image of the contours of tobacco strands.

In addition, images in Figure 5 were compared to the original images of the strands of cut tobacco (Figure 3 (a)) to examine the effect of extraction. The overlapping images are shown in Figure 6. As can be observed, a very promising extraction result using this method was obtained.

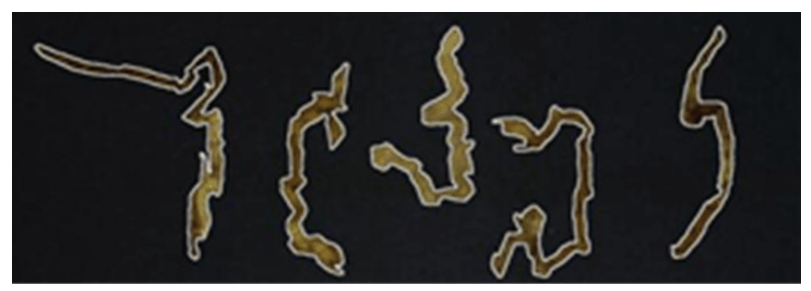

Figure 6. Image showing the overlapping contours and their original tobacco strands.

\subsection{Segmentation and detection of the line pairs at the corresponding incisions}

Straight lines on the contours of strands of cut tobacco are mostly generated by tobacco cutting machines. Line pairs on each sides of a strand of cut tobacco can reflect the width between two pieces of the cutting knife. Therefore, all the parallel line pairs on the strands' edges needed to be identified prior to the measurement of the width of cut tobacco strands for further calculation. Thus a method based on Hough's transform algorithm was proposed. All positions of feature points were first analyzed via the Hough transform method. Then a process was initiated for the parameters of possible lines where the most accessed parameter was set as the parameter of the line which the feature point located on (25). The collinear points in the image are transferred into a line using the Hough transform. Since the slope of this line could be infinite, polar coordinates were used as follows:

$$
\rho_{i}=x \cos \theta+y \sin \theta
$$

where $(x, y)$ is any point on a straight line in a rectangular coordinate system, $\rho$ is the distance from the origin to the line, $\theta$ is the angle between the positive direction of the $\mathrm{x}$ axis and the vertical line which lies between the line and the origin. And the origin of the system of coordinates is the 2D-coordinate of the image. Under such circumstances, the points in the image space exist as sinusoid in the parametric space and the lines in the image space reflect as the points of intersection in parametric space $(26,27)$. Then the image processing was conducted as follows:

1) Discretization of the parametric space: $\theta$ was selected by pulse repetition interval (number set as $M$ ) within, $[0, \pi]$ sampling number of $\rho$ was set as $Q$;

2) Accumulative array was established as $H\left(\rho_{i}, \theta_{j}\right)$ which was initialized as:

$$
H\left(\rho_{i}, \theta_{j}\right)=0
$$

where $\quad i=0,1, \ldots, M-1 ; j=0,1, \ldots, Q-1$

3) Each pixel point $\left(x_{m}, y_{n}\right)$ was processed via equation [5] into the corresponding $\left(\rho_{i}, \theta_{j}\right)$, which is as follows:

$$
\rho_{i}=x_{m} \cos \theta_{j}+y_{n} \sin \theta_{j}
$$

4) Accumulator $H\left(\rho_{i}, \theta_{j}\right)$ is defined based on the value of $\left(\rho_{i}, \theta_{j}\right)$ plus 1 , from which the maximum value of $H\left(\rho_{i}, \theta_{j}\right)$ can be found. The segmentation of lines in the image was subsequently determined based on the corresponding parameters.

By applying the Hough transform algorithm, the image of part of a strand is shown in Figure 7. It can be observed that all segmented lines were successfully identified. For clarification: all the segmented lines of the contour were highlighted with different colors

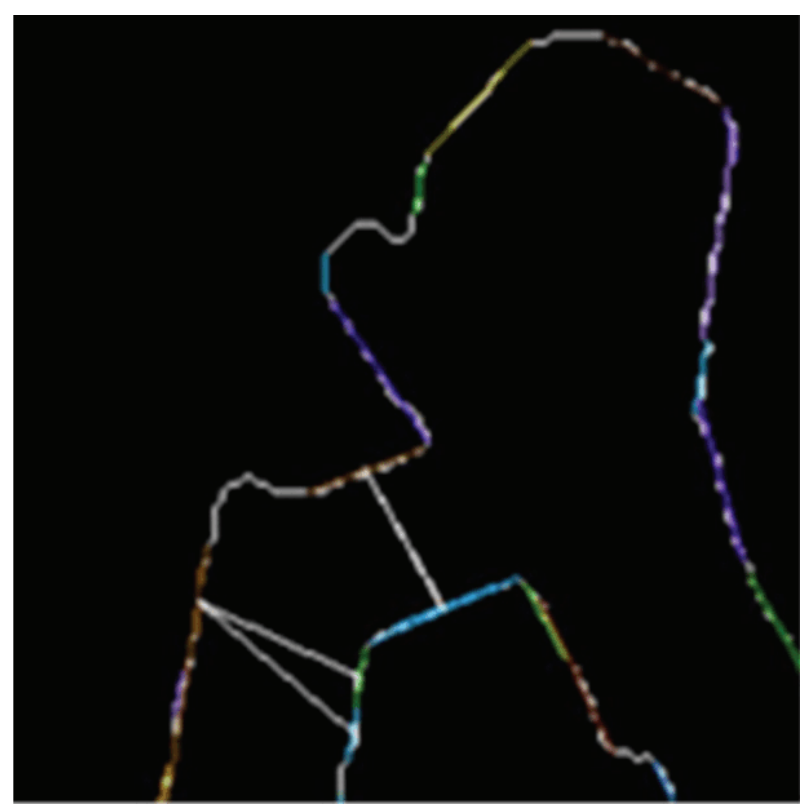

Figure 7. Image of the segmentation and detection of the line pairs. 
When all lines were successfully segmented, the related parallel line pairs were matched based on the following rules in our work:

1) Intersection angles between line segments should be less than 10 degrees; 2) The distance between line segments should not be smaller than $1.5 \mathrm{~mm}$; 3) The matched line segments must be located on both sides of the edge of the tobacco strands and no other edge between line segments is considered. As shown in Figure 7, by applying the Hough transform algorithm, all the segmented lines of the contours were highlighted with different colors. Line pairs were matched by meeting the aforementioned rules. The white lines were the ligatures of two points which lay in the middle of the two straight line segments of the contour, indicating successful matching. And the width of cut tobacco strands could be obtained by calculating the distance between the matched line segments.

\subsection{Calculation of the width of strands of cut tobacco}

During the measuring, there were lots of line segments which were almost straight on cut tobacco's edge. Two parallel straight-line segments, located on both sides over a segment of cut tobacco, were selected as width determination points. As shown in Figure 8, $L_{1}$ and $L_{2}$ are two parallel straight-line segments, which were used as an example of width-determination points. Usually, the number of line segments ranged from 10 to 100 , which depended on the specific shape of each tobacco strand.

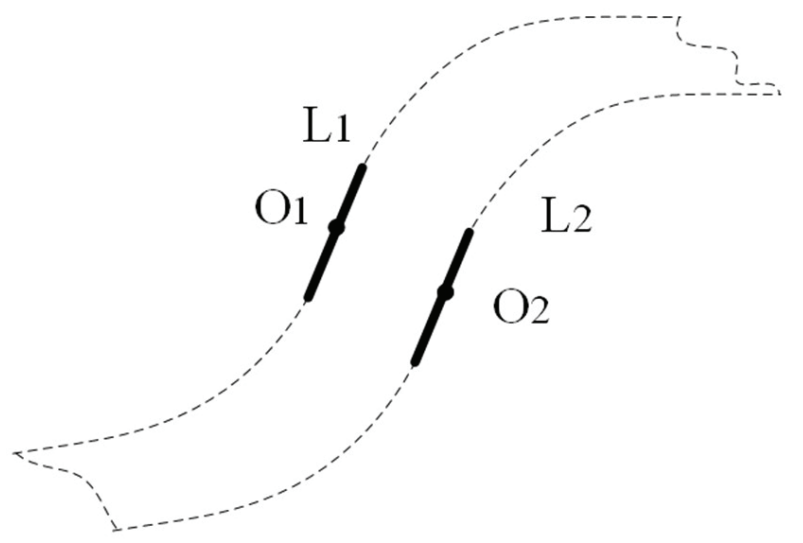

Figure 8. Sketch image of the width of determination points.

The calculation was conducted based on the following equations [7] and [8]:

$$
\begin{gathered}
d_{i}=\frac{\left(d_{i 1}+d_{i 2}\right)}{2} \\
W=\frac{\sum_{i=1}^{n} d_{i}}{n}
\end{gathered}
$$

where: $d_{i 1}$ stands for the distance from $O_{1}$ (the midpoint of the line segment $L_{1}$ ) to its parallel line segment $L_{2} ; d_{i 2}$ is the distance from $\mathrm{O}_{2}$ (the midpoint of the line segment $L_{2}$ ) to its parallel line segment $L_{1} ; d_{i}$ is the width value of the determination point; $n$ means the number of the width determination point; $W$ is the width value of the cut tobacco. The final width value of this piece of cut tobacco was determined by the statistics of all width values.

\section{RESULTS AND DISCUSSION}

\subsection{Precision}

Accuracy of this method was assessed using five samples tested by a single operator, equipment and laboratory. 30 strands of cut tobacco were measured for each test and the average value was taken as the result data. Each experiment was processed 10 times with the same 30 strands of cut tobacco. Results are shown in Table 2. Standard deviation and repeatability results exhibit that this method is valid for measuring the width of cut tobacco strands.

\subsection{Comparison with current ISO method}

\subsubsection{Test accuracy comparison}

Four ISO samples were used for the accuracy test comparison. 30 strands were measured for one test and the average value was taken as the result data. Each experiment was processed 10 times. The results are shown in Table 3 and Table 4. Slightly lower results achieved by DIP method can be observed in comparison to the ISO method, this might be attributed to two reasons: 1) the matrix used during the labeling is a $3 \times 3$ matrix, which is the smallest one. This erosion step might lead to lower results; 2) the calculated distance between two parallel lines in this method is based on the absolute perpendicular lines, which might be shorter than the lines measured manually. Anyway, comparable results obtained by both ISO method and DIP method could be observed, indicating the comparable accuracy of these two methods.

\subsubsection{Test time comparison}

30 strands were measured in one test run and the total test duration (consisting of sampling time and test time) was taken as the result data. Each experiment was processed 10 times. The results are shown in Table 4.

From Table 4, it is obvious that the DIP method is much more efficient than the current ISO method. Combined with the comparable results, this DIP method provides a promising alternative for measuring the width of strands of cut tobacco.

\section{CONCLUSIONS}

A method based on digital image processing for rapid measurement of the width of strands of cut tobacco was developed. Segmentation and extraction of cut tobacco strands were achieved by a Mean-shift algorithm. A regiongrowing algorithm based on eight-neighbors and a morphological gradient-based method were used for labeling the images of strands and the extraction of the contours. 
Table 2. Accuracy results.

\begin{tabular}{|c|c|c|c|c|c|}
\hline Number & $\begin{array}{l}\text { 'Guangdong baked' } \\
\text { (mm) }\end{array}$ & $\begin{array}{l}\text { ISO } 1 \\
(\mathrm{~mm})\end{array}$ & $\begin{array}{r}\text { ISO } 2 \\
(\mathrm{~mm})\end{array}$ & $\begin{array}{l}\text { ISO } 3 \\
(\mathrm{~mm})\end{array}$ & $\begin{array}{r}\text { ISO } 4 \\
(\mathrm{~mm})\end{array}$ \\
\hline 1 & 0.90 & 0.49 & 0.95 & 1.72 & 3.26 \\
\hline 2 & 0.97 & 0.48 & 1.03 & 1.68 & 3.16 \\
\hline 3 & 0.97 & 0.47 & 0.97 & 1.70 & 3.18 \\
\hline 4 & 0.94 & 0.50 & 1.02 & 1.65 & 3.24 \\
\hline 5 & 0.94 & 0.44 & 0.96 & 1.64 & 3.16 \\
\hline 6 & 0.90 & 0.46 & 1.02 & 1.65 & 3.16 \\
\hline 7 & 0.89 & 0.49 & 0.98 & 1.62 & 3.17 \\
\hline 8 & 0.93 & 0.48 & 1.02 & 1.67 & 3.15 \\
\hline 9 & 0.91 & 0.45 & 0.98 & 1.68 & 3.23 \\
\hline 10 & 0.93 & 0.51 & 0.98 & 1.70 & 3.19 \\
\hline SD & 0.028 & 0.022 & 0.029 & 0.031 & 0.039 \\
\hline$r$ & 0.080 & 0.063 & 0.082 & 0.088 & 0.111 \\
\hline
\end{tabular}

SD: standard deviation; $r$. repeatability

Table 3. Comparison of the average results obtained with ISO and DIP methods.

\begin{tabular}{l|c|c}
\hline Sample & $\begin{array}{c}\text { ISO method } \\
(\mathrm{mm})\end{array}$ & $\begin{array}{c}\text { DIP method } \\
(\mathrm{mm})\end{array}$ \\
\hline ISO 1 & 0.47 & 0.45 \\
ISO 2 & 1.08 & 1.00 \\
ISO 3 & 1.69 & 1.61 \\
ISO 4 & 3.40 & 3.10 \\
\hline
\end{tabular}

Table 4. Comparison of the SD values of ISO and DIP methods.

\begin{tabular}{l|c|c}
\hline Sample & $\begin{array}{c}\text { ISO method } \\
(\mathrm{mm})\end{array}$ & $\begin{array}{c}\text { DIP method } \\
(\mathrm{mm})\end{array}$ \\
\hline ISO 1 & 0.07 & 0.10 \\
ISO 2 & 0.11 & 0.12 \\
ISO 3 & 0.17 & 0.15 \\
ISO 4 & 0.39 & 0.21 \\
\hline
\end{tabular}

Table 5. Comparison between the total test time of ISO and DIP methods.

\begin{tabular}{l|c|c}
\hline Number & $\begin{array}{c}\text { ISO method } \\
(\min )\end{array}$ & $\begin{array}{c}\text { DIP method } \\
(\min )\end{array}$ \\
\hline 1 & 35 & 1.1 \\
2 & 30 & 0.98 \\
3 & 32 & 1.25 \\
4 & 27 & 1.18 \\
5 & 29 & 1.17 \\
Average & 30.6 & 1.136 \\
\hline
\end{tabular}

Furthermore, a Hough transform-based method and the related matching rules were applied to perform the selection of measuring positions and the determination of the width of cut tobacco strands. This method not only reduces the complexity and subjectivity effect during the testing procedure, but also enables the characterization of the whole strands. Most importantly, the DIP method seems to be much more efficient in comparison to the current ISO method, while producing comparable results. Therefore, this DIP method provides a promising alternative for measuring the width of strands of cut tobacco.

\section{REFFERENCES}

1. Zhang, H.L.: Effect of Width of Cut Lamina on Tar of Cigarette Smoke; Tob. Sci. Technol. (1996) 5-7. DOI: 10.16135/j.issn1002-0861.1996.05.002

2. Yang, Y., H. Gao, H. Wang, Z. Liu, Y.Z. Wang, H.J. Lin, Y.X. Cui, and Y.K. Hua: Effects of Combination of Different Width Cut Tobacco on Cigarette Physical Indexes and its Comprehensive Stability; J. Yunnan Agric. Univ. 32 (2017) 488-497.

3. Yao, G.M., W.H. Wang, X.Z. Yin, S.H. Li, and Q. Li: Effect of the Size Proportion of Cut Tobacco on the Filling Power of Cut Tobacco and Cigarette Making Quality; J. Zhengzhou Inst. Light Ind. (Nat. Sci.) 18 (2003) 62-64.

4. International Organisation of Standardization (ISO): ISO 20193:2012 — Analysis of Tobacco and Tobacco Products - Determination of the Width of the Strands of Cut Tobacco; ISO, Geneva, Switzerland, 2012. Available at: https://www.iso.org/standard/52696.html (accessed July 2019)

5. Lu, Y., T.Q. Chen, J. Chen, J. Zhang, and A. Tisler: Machine Vision Systems Using Machine Learning for Industrial Product Inspection; Proceedings of SPIE The International Society for Optical Engineering 4567 (2001) 161-170. DOI: 10.1117/12.455253

6. Lahanjar, F., R. Bernard, F. Pernuš, and S. Kovačič: Machine Vision System for Inspecting Electric Plates; Comput. Ind. 47 (2002) 113-122. DOI: $10.1016 / \mathrm{S} 0166-3615(01) 00134-8$

7. Zhang, Z.: A Flexible New Technique for Camera Calibration; IEEE Trans. Pattern Anal. Mach. Intell. 22 (2000) 1330-1334. DOI: 10.1109/34.888718

8. Kannala, J. and S.S. Brandt: A Generic Camera Model and Calibration Method for Conventional, WideAngle, and Fish-Eye Lenses; IEEE Trans. Pattern Anal. Mach. Intell. 28 (2006) 1335-1340.

DOI: 10.1109/TPAMI.2006.153

9. Mayer, A. and H. Greenspan: An Adaptive Mean-Shift Framework for MRI Brain Segmentation; IEEE Trans. Med. Imaging, 28 (2009) 1238-1250.

DOI: $10.1109 /$ TMI.2009.2013850

10. Duda, R.O. and P. E. Hart: Use of the Hough Trans- 
formation to Detect Lines and Curves in Pictures; Commun. ACM 15 (1972) 11-15.

Available at: https://www.cse.unr.edu/ bebis/CS474/ Handouts/HoughTransformPaper.pdf (accessed July 2019)

11. Xia, Y.W., Q. Feng, Y.Zhao, L. Xiang, Z. Zhu, Y. Liu, J. Liu, L. Zhang, J. Zhao, Q. Zhong, H. Yi, and R. Du: Method for Measuring Width of Tobacco Shred Based on Computer Vision; Tob. Sci. Technol. 9 (2014) 10-14. DOI: $10.3969 / \mathrm{j} . i s s n .1002-0861.2014 .09 .002$

12. Goshtasby, A.: Correction of Image Deformation From Lens Distortion Using Bezier Patches; Comput. Vision Graph. 47 (1989) 385-394. DOI: $10.1016 / 0734-189 X(89) 90120-5$

13. Brown, D.C.: Close Range Camera Calibration; Photogramm. Eng. 37 (1971) 855-866.

14. Gharib, M. and S. Ghani: Free Vibration Analysis of Linear Particle Chain Impact Damper; J. Sound Vib. 332 (2013) 6254-6264.

DOI: $10.1016 /$ j.jsv.2013.07.013

15. Eldahshan, K., M. Youssef, E. Masameer, and M.A. Mustafa: Comparison of Segmentation Framework on Digital Microscope Images for Acute Lymphoblastic Leukemia Diagnosis Using RGB and HSV Color Spaces; Biotechnol. Bioeng. 2 (2015) 27-34. DOI: $10.5120 / 15590-4426$

16. Joshi, M.D., A.H. Karode, and S.R. Suralkar: White Blood Cells Segmentation and Classification to Detect Acute Leukemia; Int. J. Emerg. Trends Technol. Comput. Sci. 2 (2013) 147-151. Available at: http://citeseerx.ist.psu.edu/viewdoc/download?doi= 10.1.1.387.699\&rep=rep1\&type $=$ pdf $($ accessed August 2019)

17. Cheng, Y.Z.: Mean Shift, Mode Seeking, and Clustering; IEEE Transactions on Pattern Analysis and Machine Intelligence 17 (1995) 790-799.

DOI: $10.1109 / 34.400568$

18. Zhang, Y.C., H. Guo, F. Chen, and H. Yang: Weighted Kernel Mapping Model With Spring Simulation Based Watershed Transformation for Level Set Image Segmentation; Neurocomputing 249 (2017) 1-18. DOI: 10.1016/j.neucom.2017.01.044

19. Strang, G.: Linear Algebra and its Applications; $3^{\text {rd }}$ edition, Harcourt, Brace, Jovanovic, San Diego, CA, USA, 1988. ISBN-13: 978-0155510050

20. Rosenfeld, A. and J.L. Pfaltz: Sequential Operations in Digital Picture Processing; JACM 13 (1966) 471-494. DOI: $10.1145 / 321356.321357$
21. Bhattacharya, P.: Connected Component Labeling for Binary Images on Reconfigurable Mesh Architectures; J. Syst. Architect. 42 (1996) 309-313. DOI: 10.1016/1383-7621(96)00027-6

22. Samet, H.: Connected Component Labeling Using Quadtrees; JACM 28 (1981) 487-501. Available at: https://www.cs.umd.edu/users/hjs/pubs/SametJACM 81.pdf (accessed July 2019)

23. He, X.G., J. Tian, L.F. Wu, and Y.Y: Zhang: Illumination Normalization with Morphological Quotient Image; J. Softw. 18 (2007) 2318-2325. DOI: $10.1360 /$ jos 182318

24. Li, X.F., D.W. Ma, and Y.J. Nian: The Research on Algorithm of Image's Erosion and Dilation; Image Technol. 01 (2005) 37-39.

DOI: 10.3969/j.issn.1001-0270.2005.01.009

25. Cheng, J., Q. Liu, and H. Lu: Texture Classification Using Kernel Independent Component Analysis; Proceedings of the $17^{\text {th }}$ International Conference on Pattern Recognition 1 (2004) 23-26. DOI: $10.1109 /$ ICPR.2004.1334231

26. Liu X.W. and L. Cheng: Independent Filters for Texture Classification; Proceedings of IEEE International Conference on Image Processing 3 (2002) 24-28. DOI: $10.1109 /$ ICIP.2002.1038917

27. Liu, X. and L. Cheng: Independent Spectral Representations of Images for Recognition; J. Opt. Soc. Am. A 20 (2003) 1271-1282.

DOI: $10.1364 / J O S A A .20 .001271$

Corresponding author:

Qian Feng

Zhengzhou Tobacco Research Institute of CNTC

Zhengzhou, Henan

China

Email:feng@ztri.com.cn 